\title{
À LUZ DE UMA REVOLTA: A FESTA E O AFTER DE THE BOYS IN THE BAND
}

\author{
Markus Volker Lasch ${ }^{1 *}$ \\ Renato Barreto Pereira ${ }^{1 * *}$ \\ ${ }^{1}$ Universidade Federal de São Paulo, São Paulo, SP, Brasil
}

\begin{abstract}
Resumo
Este artigo analisa a transformação na recepção crítica da peça The Boys in the Band, de Mart Crowley, enfocando-se o período transcorrido entre o lançamento da peça, em 1968, e sua versão cinematográfica, em 1970. Parte-se de uma breve contextualização e análise dos aspectos pioneiros da obra e de suas adaptações, assim como de suas reavaliações suscitadas pelos acontecimentos históricos circundantes, em especial à Revolta de Stonewall, marco para o Movimento LGBTQI+, ocorrida em 1969. No contexto de análise da recepção do texto original de Crowley, serviram de apoio reflexões de Hans Robert Jauss sobre o horizonte de expectativas dos leitores e aquele suscitado por uma obra literária.

Palavras-chave: Teatro; Cinema; Movimento Gay; Adaptação; Horizonte de expectativas.
\end{abstract}

\section{IN LIGHT OF A RIOT: THE PARTY AND AFTER-PARTY OF THE BOYS IN THE BAND}

\begin{abstract}
This article analyzes the transformation in the critical reception of the play The Boys in the Band, by playwright Mart Crowley, and of its cinematographic version, focusing on the short period between the launch of the play in 1968 and the film in 1970. It starts with a brief historical contextualization and an analysis of the pioneering aspects of the work and its adaptations, as well as its critical reevaluations raised by the weight of the surrounding historical events, in particular the Stonewall riots, an important milestone for the LGBTQI+ Movement worldwide, which took place in 1969. In the context of analyzing the reception to Crowley's original text, reflections by the critic Hans Robert Jauss on the horizon of expec-
\end{abstract}

\footnotetext{
"Doutor em Literatura Geral e Comparada pela Universidade Livre de Berlim. Professor Associado da Universidade Federal de São Paulo (UNIFESP). Seu e-mail é: marklasch@gmail.com. ORCID: https://orcid. org/0000-0001-8553-9598.

** Bacharel e licenciado em Letras pela Universidade de São Paulo (USP). Mestrando em Teoria Literária pela Universidade Federal de São Paulo (UNIFESP). Seu e-mail é: barreto.renato2@gmail.com. ORCID: https:// orcid.org/0000-0002-6816-6643.
} 
tations - of the readers and the one raised by a literary work - served as theoretical support.

Keywords: Theater; Cinema; Gay Movement; Adaptation; Horizon of expectations 


\section{Introdução}

Lançada em 1968, The Boys in the Band, em português Os rapazes da banda, peça do dramaturgo Mart Crowley (1935-2020), marca uma importante transição na representação de pessoas homossexuais no teatro, colocando personagens gays e suas histórias no centro da narrativa de um jeito inédito nos palcos mainstream dos Estados Unidos e alhures.

À época, a peça oferecia ao público um retrato sem precedentes do que seria uma "vida gay normal", algo inexistente, ignorado ou vilipendiado tanto no teatro quanto na sociedade de forma mais ampla. Com isso, a recepção calorosa ao texto de Crowley e à sua encenação original refletia uma crescente atenção dada a grupos minoritários - aspecto observado ao longo da efervescência cultural da década de 1960 - e também a valorização de uma nova forma de se abordar, nos palcos, tabus ainda existentes na sociedade daquele período. No entanto, apesar de seu caráter inovador e do alinhamento com outras produções de vanguarda contemporâneas, pouco tempo após o seu lançamento e antes de sua adaptação cinematográfica estrear nos cinemas em 1970, The Boys in the Band passou a ser referenciada não pela inovação textual e formal, mas por seu anacronismo. A obra divergiria da ideia de "orgulho gay" e das ações afirmativas construídas ao longo da década que eclodiram com a Revolta de Stonewall, um marco para o Movimento LGBTQI $+{ }^{1}$ em todo o mundo. A partir daí, tais visões críticas e desditosas se sobrepuseram, fazendo com que The Boys in the Band passasse a ser encarada negativamente por gays liberacionistas e críticos de cultura ao longo das décadas seguintes, até que visões renovadas tanto sobre a peça quanto sobre o filme começassem a emergir.

Considerando-se esse panorama, o presente artigo analisa, a partir da recepção original da peça, como as visões sobre ela se transformaram em um curto período de tempo a ponto de, apenas dois anos após o seu lançamento, ela ser considerada uma "peça de época". Parte-se de uma breve contextualização e de uma análise dos aspectos inovadores da obra e suas adaptações, assim como de suas reavaliações críticas suscitadas pelo peso dos acontecimentos históricos circundantes. No contexto de análise da recepção ao texto original de Crowley, serviram de apoio as reflexões de Hans Robert Jauss (1994) sobre horizonte de expectativas - dos leitores e aquele suscitado por uma obra literária.

\section{2. $O$ contexto}

Qual é o tempo de uma obra literária? Segundo o crítico Roberto Schwarz, os ponteiros do relógio da história são as obras de arte (SCHWARZ, 2014). Em tal relógio, o lançamento de The Boys in the Band apontaria para um momento de diversas transformações socioculturais nos Estados Unidos e no resto do mundo que marcariam as ideias por trás do que é comumente entendido por "anos 60", em especial no contexto de insurgência de lutas pelos direitos civis, como o Movimento Gay, e da construção de subjetividades sexuais dissidentes. Dito isso, é 
quase impossível analisar a peça sem remeter ao contexto histórico adjacente e retomar o impacto dos acontecimentos turbulentos que ocorreriam no final da década em sua recepção crítica.

Segundo o crítico Fredric Jameson, naquele período, uma gama de respostas variadas e de inovações criativas mostraram-se possíveis, ainda que dentro de limites historicamente impostos: "Os anos 60 tinham que acontecer como aconteceram e [...] suas oportunidades e fracassos estavam inextricavelmente interligados, marcados pelas restrições e possibilidades objetivas proporcionadas por determinada situação histórica" (JAMESON, 1991, p. 81). Em sua análise, uma dessas situações objetivas comuns seria o levante das minorias marginalizadas, trazendo à frente do debate social e político a emergência de novos "sujeitos da história" que começam, então, a reivindicar e a utilizar suas vozes, inclusive nas produções culturais.

Mart Crowley, falecido em 2020, aos 84 anos, escreveu The Boys in the Band em 1967. Apenas um ano antes, o crítico Stanley Kauffman escrevera um ensaio de grande repercussão apontando que, embora muitos dramaturgos fossem gays, o drama que escreviam não abordava seu mundo de maneira direta, provocando -os, assim, a escreverem sobre as suas próprias realidades (KAUFFMAN, 1966). Crowley, que naquele momento havia realizado apenas tentativas de escritas malsucedidas para a televisão, estava entre os que ficaram chocados com o apelo do artigo por uma dramaturgia mais aberta. "O artigo de Kauffman foi como, 'já não é hora de um desses escritores homossexuais escreverem uma peça que seja aberta sobre a sua própria experiência?'. E achei que aquele era um ponto muito, muito bom" (STONEWALL, 2009, nossa tradução²).

A estreia ocorreria nos palcos de Nova York em 1968, um ano marcante para a cultura dos Estados Unidos e do mundo ${ }^{3}$. Apenas dois anos depois, em 1970, o sucesso da peça culminaria no lançamento de sua versão cinematográfica, dirigida por William Friedkin - mais conhecido por ter dirigido O Exorcista (1973) - com o mesmo elenco original da peça. As filmagens aconteceram durante a primavera e o início do verão de 1969. Em determinada cena, em uma inscrição feita com giz na parede, lê-se "verão de 1968", um indicador de que o filme era, de fato, o retrato de um passado muito próximo.

Entre esses dois momentos, em 1969, aconteceria um dos eventos mais relevantes para a história do Movimento LGBTQI+: a Revolta de Stonewall, ocorrida na noite de 28 de junho, cujo epicentro fora o bar Stonewall Inn, localizado ao sul da ilha de Manhattan ${ }^{5}$. A revolta provocou tamanha ruptura e transformação social a ponto de influenciar, em certa medida, a recepção ao texto de Crowley nos anos e nas décadas seguintes, independentemente das mídias às quais ele havia sido adaptado. Naquele ponto, a militância homossexual já discordava da representação que a obra fazia da "cultura gay" e, em meados dos anos 1970, The Boys in the Band havia se tornado um retrato de "gays velhos" e marcados por traços como sexualidades enrustidas, autodepreciação e disfunções de uma cultura gay masculina anterior a Stonewall.

Até então, o preconceito era institucionalizado nos Estados Unidos, visto que, em grande parte dos estados, havia legislações discriminatórias e até a 
criminalização da homossexualidade, muito em decorrência da associação estabelecida pelas autoridades entre "homossexualismo" e comunismo, na esteira da perseguição promovida, sobretudo, a partir da década de 1950 (D'EMILIO, 1998). Nos anos 1960, o silenciamento dos gays ocorreu pela via médica, com a homossexualidade sendo considerada doença mental, legal, com a criminalização de práticas homossexuais, e religiosa,com a homossexualidade sendo vista como abominação (WESTSTRATE; MCLEAN, 2010). Contudo, o efeito colateral foi o início de uma resistência organizada em busca de mudanças legais e aceitação, culminando simbolicamente com os episódios em torno de Stonewall, que se tornariam marco de uma militância mais combativa e firmada na ideia de orgulho gay (QUINALHA, 2019).

Assim, a peça e o filme serviram como pontos de referência comuns para muitos críticos e escritores queer do final dos anos 1960 e 1970. Em artigo publicado em 1969, a versão teatral de The Boys in the Band foi usada especificamente para marcar uma guinada cultural entre a "velha" e a "nova homossexualidade" (BURKE, 1969, p. 178, nossa tradução ${ }^{6}$ ). Por sua vez, em livro publicado em 1971, a peça de Crowley foi citada como exemplo de "uma homossexualidade não liberada" (ALTMAN, 1993, p. 178, nossa tradução ${ }^{7}$ ). Tendo ajudado a quebrar tabus, The Boys in the Band, agora, tornara-se ela mesma um tabu.

\section{A obra}

A história gira em torno dos acontecimentos de uma única noite que ocorrem no mesmo espaço e em torno do mesmo evento. Michael, um dos protagonistas, dá uma festa em seu apartamento junto a seis amigos e a um convidado surpresa para celebrar o aniversário de um deles, Harold. Nesse ínterim, de forma inesperada, junta-se ao evento um antigo colega de faculdade de Michael, o heterossexual Alan. Com isso, o que se inicia como um reencontro festivo entre convivas - a maior parte deles entre o final dos 20 e início dos 30 anos de idade acaba por se tornar uma ocasião reveladora e cruel para que questões complexas como racismo, homofobia, promiscuidade, envelhecimento, rejeição, objetificação sexual, entre outras, venham à tona com o passar da noite e o surgimento de questões íntimas das personagens em cena.

De forma geral, The Boys in the Band (CROWLEY, 2008) apresenta ao público uma visão sobre a homossexualidade baseada na diversidade de perfis dos personagens em cena. A pluralidade dos personagens, em termos de aspectos como raça e etnicidade, ocupações, modos de ser e natureza de suas relações, é bastante heterogênea: há melhores amigos (Michael e Harold); ex-amantes (Michael e Donald); excolegas de quarto (Michael e Alan); ex-amantes casuais (Donald e Larry); um casal poliamoroso (Larry e Hank); um homossexual efeminado (Emory); um homossexual negro (Bernard); um garoto de programa (Cowboy); um heterossexual ambíguo (Alan); e, claro, o próprio círculo de amizades - amplo e plural, mas muito íntimo.

A narrativa segue uma estrutura de dois atos com um intervalo. $O$ primeiro apresenta os convidados no apartamento de Michael, culminando na agressão 
homofóbica de Alan contra Emory e na chegada tardia de Harold, o aniversariante. O segundo ato, que se passa principalmente no terraço do apartamento, apresenta as convenções de uma festa de aniversário e uma tempestade que força todos a retornarem para dentro do local. Na sequência, até o final da peça, a narrativa se centra no jogo cruel inventado por Michael, já alcoolizado e descontrolado, em que cada jogador deve fazer uma ligação telefônica para confessar ou reafirmar seu amor por outra pessoa, custe o que custar, o que os leva a uma espécie de sessão de terapia coletiva não convencional.

\subsection{A forma da obra}

No aspecto formal, a obra de Crowley (2008) rompe com convenções narrativas em voga na dramaturgia produzida e encenada à época, no contexto de peças que tratavam da homossexualidade. Naquele contexto, as problem plays [peças-problema] eram a única via em que o tema era tratado seriamente no teatro: uma questão social ou moral era trabalhada pelo dramaturgo e "solucionada" no palco. Isso representava uma herança do drama realista ou naturalista na medida em que o destino da personagem gay, ali, era a morte, com frequência por suicídio (CLUM, 2000). Essa forma de aniquilamento também foi um desfecho comum em romances das décadas de 1930 e 1960 como artifício para a restauração do equilíbrio social nas narrativas (FONE, 2000). Esse mesmo fato aparece em uma das falas de Michael, em que ele afirma que "Nem sempre é como nas peças, nem todas as bichas se matam no final da história" (CROWLEY, 2008, p. 71, nossa tradução $\left.{ }^{8}\right)$.

No contexto dos estudos sobre teatro e cinema LGBTQI+, B. Ruby Rich, estudiosa do chamado new queer cinema, afirma que o mesmo também ocorria nos filmes realizados pré-liberação gay:

Considere o estado dos filmes de "gays e lésbicas" nos Estados Unidos antes de 1969. Provavelmente não existia tal coisa, apenas uma dispersão de diretores gays e lésbicas, muitas vezes, enrustidos, fazendo filmes disfarçados para o mercado de massa como heterossexuais, embora com o ocasional ator gay ou atriz lésbica ou uma piscadela sutil. Se os personagens foram abertamente identificados como gays ou lésbicas na tela, na maioria das vezes, era para uma piada ou morte trágica (RICH, 2013, p. 3 , nossa tradução ${ }^{9}$ ).

Nesse intento, The Boys in the Band valoriza, explicita e veicula uma estética de identificação que busca ser, portanto, representativa de um grupo social em uma miríade de identidades possíveis. Essa fragmentação justapõe o texto literário à realidade social que ele, por assim dizer, representa. Ou seja, um dos aspectos mais fortes da obra é justamente despir as pretensões das personagens, em especial a partir do último ato, revelando um pessimismo latente e honesto que se torna, por sua vez, uma afirmação de vida. O texto de Crowley dribla a prática, comum até então, de construção de personagens gays apresentados como víti- 
mas, conferindo-lhes, por oposição, um caráter transgressor pela própria possibilidade de permanecerem vivos até o fim como sujeitos de desejo e de conflitos.

Ademais, a sexualidade não é tomada como característica absoluta desses indivíduos, mas, sim, um traço que os une em sua humanidade. Segundo depoimento de um dos poucos atores ainda vivos, Laurence George Luckinbill, que interpreta Hank, em documentário sobre a versão cinematográfica (MAKING..., 2010), o caráter universal de The Boys in the Band deve-se ao fato de que tanto a peça quanto o filme representam um recorte de vida ordinário, marcado por afeto, jogos mentais e dramas humanos não limitados a/por categorias sexuais. E esse traço de realidade social é o que conforma a obra literária. Personagens apresentados como um grupo, mas também como registro das recém-liberadas identidades e mundos sociais apesar da homofobia ${ }^{10} \mathrm{e}$ do heteropatriarcado - ponto de conflito representado pelo único personagem tido como heterossexual na história, Alan.

Assim, se, por um lado, é inexistente a necessidade moralizante de vitimizar personagens gays, por outro, eles não ensejam nenhuma representação explícita de "orgulho gay", um aspecto que, dos anos 1950 em diante, sobretudo a partir de Stonewall, ganha destaque no Movimento LGBTQI+, permanecendo até hoje atrelado às manifestações que ocorrem em todo o mundo ${ }^{11}$.

Por isso, Crowley, em termos formais e de convenção dramatúrgica, constrói personagens que, de certa forma, contrariavam ou feriam esse orgulho ao exibirem facetas confusas, contraditórias e fragmentadas de suas personalidades, refletindo claramente a "confusão" transicional pela qual passava o mundo ao adentrar o período identificado por teóricos como Fredric Jameson como pósmodernidade, marcado pela terceira fase de desenvolvimento do capitalismo (JAMESON, 2002).

Essa relação pode ser percebida na visão jamesoniana sobre marxismo e forma (JAMESON, 1985), segundo a qual a influência da matéria-prima social recai não apenas sobre o conteúdo, mas também sobre a própria forma das obras literárias. Isso corresponde a dizer que, na literatura pós-moderna, as próprias personagens tornam-se problemáticas, e a escolha dos traços pessoais - como heróis coléricos e cínicos, tais quais os personagens de Crowley - exige uma justificação orgânica no interior da própria obra. Sob esse aspecto, retratar um grupo de amigos chafurdados em seus problemas pessoais coloca os personagens como opostos a uma lógica produtiva, que já os considerava malditos ou outsiders, e os situa como identidades destoantes dentro da lógica capitalista.

Mais ainda, The Boys in the Band guarda semelhanças com outros importantes textos dramáticos do mesmo período, como Quem tem medo de Virginia Woolf?, de Edward Albee (1962), e And Things That Go Bump in the Night [E as coisas que fazem barulho à noite], de Terrence McNally (1965), partilhando o tom naturalista, a pouca empatia gerada pelos personagens principais, a presença de surtos e perda de controle, a linguagem ácida e os jogos mentais, além da presença simbólica das salas de estar como espaços catalisadores de crises dentro das narrativas. Além disso, ambos os dramaturgos, Albee e McNally, assim como Crowley, inserem-se no panteão de autores assumidamente gays catapultados à 
notoriedade naquela década e que viriam a se tornar ícones LGBTQI+ ao longo de suas carreiras.

\subsection{Entre mídias, espaços e tempos}

Apesar dos elementos em comum, é necessário destacar as distinções inerentes aos formatos teatral e fílmico que marcam as adaptações de The Boys in the Band, as quais, por sua vez, também guardam relação com a própria variação na recepção do texto ao longo do tempo no teatro e no cinema.

A adaptação do texto original da peça para roteiro cinematográfico, assim como a própria produção do filme, contou com a participação direta de Mart Crowley. Na comparação entre os dois scripts, nota-se poucas diferenças nos diálogos, uma vez que a quase totalidade das falas foi mantida ipsis litteris, "deixando seu foco narrativo na vida social pré-liberação gay totalmente intacto” (POWELL, 2016, p. 88, nossa tradução ${ }^{12}$ ). Da mesma forma, o fato de o elenco ter permanecido o mesmo da encenação inicial aponta para o desejo de Crowley de que The Boys in the Band, com todas as suas especificidades enquanto formato fílmico, fosse uma transposição muito próxima em termos de conteúdo, imagem e nas próprias atuações dos atores escalados:

O sucesso da peça levou sua adaptação a outras mídias. Em 1969, a A\&M Records lançou uma gravação original do elenco de The Boys in the Band como um LP duplo. Os produtores de Hollywood expressaram interesse em adaptar a peça para o cinema, mas Crowley recusou as mudanças que eles propuseram e decidiu produzir o filme por conta própria. A unidade de produção de filmes da CBS naquele período, a Cinema Center Films, concordou com os termos de Crowley: as filmagens ocorreriam na cidade de Nova York, permaneceria o elenco original da peça, o próprio Crowley adaptaria o roteiro, e nenhuma canção diegética ou partituras musicais seriam incluídas (BELL, 2016, p. 4, nossa tradução ${ }^{13}$ ).

Tamanho havia sido o sucesso da peça apenas um ano antes que a intenção dos produtores, com o aval do autor, era replicar o sucesso daquela temporada inicial agora em uma escala maior. Nesse sentido, não se pode afirmar que o filme é apenas uma réplica da peça:

Adaptação é repetição, mas repetição sem replicação. E há, manifestamente, muitas intenções possíveis por trás do ato de adaptação: o desejo de consumir e apagar a memória do texto adaptado ou de questioná-lo é tão provável quanto o desejo de homenagear copiando (HUTCHEON, 2006, p. 7, nossa tradução $\left.0^{14}\right)$.

A peça e o filme passam a ser avaliados de formas muito próximas. Com isso, no caso das resenhas, é comum observar comentários que o identificam como sendo "filme de teatro" ou carregado de "falas teatrais", assim como menções por vezes mais frequentes ao autor da peça do que ao diretor da adaptação cinematográfica (BELL, 2016). Esse destaque às origens e ao tom do texto acaba por 
diferenciar The Boys in the Band (filme) em relação à própria expectativa do que difere a adaptação cinematográfica de uma obra literária. Nesse sentido, segundo o romancista John North,

Escrever um roteiro baseado em um grande romance é principalmente um trabalho de simplificação. [...] Um filme tem que passar sua mensagem por imagens e relativamente poucas palavras; esse formato tem pouca tolerância para complexidades ou ironias ou tergiversações. (BEGLEY, 2003, apud HUTCHEON, 2006, p. 2, nossa tradução ${ }^{15}$ ).

No aspecto espacial, se na peça toda a ação se desenvolve em um único cenário (o apartamento duplex de Michael), no filme esse mesmo locus é mantido. Embora a câmera acompanhe as personagens em diferentes cômodos do apartamento, continua sendo ali o epicentro da narrativa.

A estrutura narrativa do roteiro, a montagem e os recursos cinematográficos utilizados por Friedkin permitem que, logo no início do filme, seja introduzido um elemento substancialmente diferente em relação à peça: nos minutos iniciais são exibidas cenas dos personagens em locais externos ao apartamento (loja, bar, estacionamento, táxi, hotel, entre outros), expondo o espectador a traços da vida cotidiana dos convidados que precedem a sua chegada ao local da festa:

Mostrar os gays como parte de locais comuns e triviais era remodelar esses locais em termos teleológicos progressivamente orientados; imagens de pessoas gays na cidade funcionaram como parte de uma maior fabricação cinematográfica de saída do armário que implicitamente narrativizou uma transformação gay (POWELL, 2016, p. 93, nossa tradução ${ }^{16}$ ).

Na peça, o primeiro ato se inicia com Michael já interagindo, na entrada do apartamento, com o primeiro convidado a chegar, Donald; no filme, essa interação ocorre inicialmente através de uma ligação telefônica. Quando todos os demais personagens começam a chegar ao apartamento, tal qual a encenação nos palcos, os dois scripts (da peça e do filme) coincidem. Entretanto, resta evidente que, embora o texto no palco e no cinema seja quase idêntico, cada formato ou mídia carrega suas próprias possibilidades de criação narrativa e visual:

Uma consideração das diferenças entre os modos de engajamento de narrar e mostrar, entretanto, sugere [que] cada modo, como cada meio, tem sua própria especificidade, se não sua própria essência. Em outras palavras, nenhum modo é inerentemente bom em fazer uma coisa e não outra; mas cada um tem à sua disposição diferentes meios de expressão - mídia e gêneros - e, portanto, pode almejar e alcançar certas coisas melhor do que outros (HUTCHEON, 2006, p. 24, nossa tradução ${ }^{17}$ ).

No caso das traduções e adaptações em outros países, o próprio texto adaptado varia de acordo com a mídia: no caso das versões brasileiras, o texto traduzido por Millôr Fernandes em 1970 para a peça não é o mesmo que foi utilizado, por exemplo, na legendagem do filme. Mas, além disso, as adaptações 
fora dos Estados Unidos também guardam peculiaridades em relação à própria recepção da peça:

Enquanto The Boys in the Band foi considerada uma peça homossexual ao atravessar os Estados Unidos, no exterior foi considerada uma peça homossexual americana. Na verdade, muitos dos críticos fizeram um grande esforço para explicar que os personagens eram distintamente estrangeiros. O público local foi encorajado a entrar no mundo da peça como se fossem turistas em uma terra estranha com uma visão privilegiada dos costumes, comportamentos e rituais dos aborígenes americanos (WILSON, 2016, p. 149 , nossa tradução $\left.{ }^{18}\right)$.

Além disso, as várias instâncias de adaptação observadas no caso de The Boys in the Band, a saber, o texto dramático passado a encenação teatral e, depois, a narração fílmica e, ainda, as novas montagens em outros países com idiomas diferentes, apontam para particularidades a serem investigadas, que distinguem cada encarnação da obra de Crowley em variações de tempo e espaço.

\section{Uma mudança de horizonte}

Quando estreou no circuito alternativo do teatro nova-iorquino, The Boys in the Band causou alvoroço entre o público homo e heterossexual, recebendo resenhas positivas e, fato inédito, sensíveis de críticos de veículos de comunicação mainstream. Segundo registros, a peça atingiu o marco de mil encenações e foi um sucesso comercial. A crítica publicada no dia seguinte pelo The New York Times (BARNES, 1968) já indicava o quanto a peça oferecia ao público algo inédito ao afirmar que o texto não tratava exclusivamente de homossexuais, mas que utilizava o modo de vida homossexual como paradigma válido para espelhar a existência humana.

Contudo, embora inovadora, pouco mais de um ano depois, tornou-se evidente que The Boys in the Band não seria universalmente abraçada. Com o movimento pelos direitos civis das pessoas homossexuais se desenvolvendo rápida e vocalmente enquanto a peça ainda estava em meio à sua temporada inicial e, durante a produção do filme, alguns críticos a atacaram por apresentar uma imagem dos homossexuais não lisonjeira e carregada de autodepreciação. Já no contexto do lançamento da versão cinematográfica, afirmou-se que:

Os liberacionistas gays das décadas de 1970 e 1980 repudiaram ativamente o filme, construindo uma má reputação duradoura para ele; às vezes, mesmo agora, o próprio título de The Boys in the Band tem servido de taquigrafia para uma consciência masculina gay pré-liberalizada, caracterizada por autoaversão, insularidade e narcisismo (BELL, 2016, p. 11, nossa tradução ${ }^{19}$ ).

A ironia e o sarcasmo do personagem principal, Michael, soam bastante destoantes no contexto: ao final da peça, há a notória fala: "Me mostre um homos- 
sexual feliz e eu the mostrarei um cadáver gay" (CROWLEY, 2008, p. 112, nossa tradução $\left.{ }^{20}\right)$. Apresentar personagens imperfeitos, retratando-os como indivíduos que espelhavam o caráter problemático e fragmentário próprio de seu tempo, não corroborava de maneira incontestável um orgulho gay então em construção, ainda que, com o distanciamento histórico atual, seja possível rever o que foi apontado como estereotipação na obra de Crowley e problematizar a suposta homofobia internalizada depreendida do comportamento e das falas dos personagens.

É digno de nota que, embora a ebulição dos anos 1960 tenha fomentado a liberação gay, dentro desse grupo, ainda se replicava a lógica discriminatória da sociedade em geral, visto que os gays efeminados, os gays negros e as travestis, por exemplo, eram sistematicamente criticados e estigmatizados mesmo entre seus pares por destoarem do padrão de norma social idealizado para os gays recém-liberados. Esse paradoxo está presente em The Boys in the Band na relação dos personagens Emory e Bernard, um gay efeminado e um gay negro, respectivamente, em relação ao restante do grupo.

Embora seja possível considerar que o filme de Friedkin "eternizou" a peça e a levou a novos públicos, a influência de Stonewall se fez sentir nas críticas dirigidas a ambas as versões, especialmente porque o ano de 1970 marcaria tanto a estreia do filme quanto o encerramento da primeira temporada da peça. Nas críticas, contudo, mais do que atacar os diretores ou as atuações do elenco, o elemento comum era o ataque, sobretudo, ao texto de Mart Crowley e o que ele agora representava.

Dessa forma, percebe-se que, em um curto intervalo de tempo, houve uma mudança considerável e marcante no tocante à recepção de The Boys in the Band. Abordando aqui, especificamente, o recorte da recepção ao texto original enquanto obra literária, em meio aos dois polos - o sucesso inicial de crítica e público na versão teatral e a sua renegação por parte de críticos e ativistas do Movimento Gay pouco mais de um ano depois, em parte instigada pela estreia do filme nesse ínterim - há um continuum de implicações estéticas e históricas.

Nesse sentido, no tocante à relação entre uma obra literária e o seu tempo, Hans Robert Jauss afirma que:

A relação entre literatura e leitor possui implicações tanto estéticas quanto históricas. A implicação estética reside no fato de já a recepção primária de uma obra pelo leitor encerrar uma avaliação de seu valor estético, pela comparação com outras obras já lidas. A implicação histórica manifestase na possibilidade de, numa cadeia de recepções, a compreensão dos primeiros leitores ter continuidade e enriquecer-se de geração em geração, decidindo, assim, o próprio significado histórico de uma obra e tornando visível sua qualidade estética (JAUSS, 1994, p. 23, nossos grifos).

Nesse sentido, percebe-se que, à época, o caráter vanguardista do texto de Crowley não passou incólume pela crítica especializada e pelo público, sendo inicialmente encarado como algo inovador. Esse aspecto se relaciona, dessa forma, ao conceito literário do horizonte de expectativas. Segundo o e-Dicionário de Termos Literários: 
O horizonte é, basicamente, o modo como nos situamos e apreendemos o mundo a partir de um ponto de vista subjetivo; o horizonte de expectativas é uma característica fundamental de todas as situações interpretativas, dizendo respeito a uma espécie de fatalismo que acompanhará qualquer ponto de vista face à visão que temos do mundo: quando interpretamos, possuímos já um conjunto de crenças, de princípios assimilados e ideias aprendidas que limitam desde logo a liberdade total do ato interpretativo; por outras palavras, quando lemos um texto literário, o nosso horizonte de expectativas atua como a nossa memória literária feita de todas as leituras e aquisições culturais realizadas desde sempre (CEIA, 2009).

O horizonte de expectativas, portanto, poderia ser entrevisto na forma costumeira com que a questão da homossexualidade vinha sendo representada no teatro e também na ruptura provocada pela peça. Por essa visão,

A obra que surge não se apresenta como novidade absoluta num espaço vazio, mas, por intermédio de avisos, sinais visíveis e invisíveis, traços familiares ou indicações implícitas, predispõe seu público para recebê-la de uma maneira bastante definida. Ela desperta a lembrança do já lido, enseja logo de início expectativas quanto a "meio e fim", conduz o leitor a determinada postura emocional e, com tudo isso, antecipa um horizonte geral da compreensão vinculado, ao qual se pode, então - e não antes disso -, colocar a questão acerca da subjetividade da interpretação e do gosto dos diversos leitores ou camadas de leitores (JAUSS, 1994, p. 28).

A "mudança de horizonte", no caso, também guarda relação com o próprio valor estético da obra. Tanto a forma quanto o conteúdo literário indicam a apreciação de The Boys in the Band no momento em que a peça foi lançada, nos anos imediatamente após o seu lançamento e ao longo das décadas seguintes:

A maneira pela qual uma obra literária, no momento histórico de sua aparição, atende, supera, decepciona ou contraria as expectativas de seu público inicial oferece-nos claramente um critério para a determinação de seu valor estético. A distância entre o horizonte de expectativa e a obra, entre o já conhecido da experiência estética anterior e a "mudança de horizonte" exigida pela acolhida à nova obra, determina, do ponto de vista da estética da recepção, o caráter artístico de uma obra literária (JAUSS, 1994, p. 31).

Sob esse aspecto, tem-se que o horizonte de expectativas relacionado à obra passou por transformações consideráveis em um curto período, de tal forma que a visão negativa a seu respeito prevaleceu entre críticos culturais e ativistas pelas décadas seguintes. Entende-se que:

Quando, então, o novo horizonte de expectativas logrou já adquirir para si validade mais geral, o poder do novo cânone estético pode vir a revelar-se no fato de o público passar a sentir como envelhecidas as obras até então de sucesso, recusando-lhes suas graças (JAUSS, 1994, p. 33). 
Buscar entender o impacto da obra no contexto de seu lançamento envolve, portanto, retomar o afeto inicial que desaparecera para o público nos anos seguintes, além de buscar compreender as transformações em jogo. Nesse sentido, segundo Jauss (1994), o horizonte de expectativas é mutável ao longo do tempo o que possibilita, por exemplo, a nova onda de revisitações a que a peça tem sido exposta nos últimos anos:

Se, inversamente, trata-se de avaliar o caráter artístico de uma obra pela distância estética que a opõe à expectativa de seu público inicial, segue-se daí que tal distância - experimentada de início com prazer ou estranhamento, na qualidade de uma nova forma de percepção - poderá desaparecer para leitores posteriores, quando a negatividade original da obra houver se transformado em obviedade e, daí em diante, adentrado ela própria, na qualidade de uma expectativa familiar, o horizonte da experiência estética futura (JAUSS, 1994, p. 32).

A obra de Crowley, assim, respondeu ao chamado de um determinado momento histórico, abordando direta e indiretamente questões que permanecem relevantes até os dias correntes. Uma análise menos enviesada do texto original revela que o texto aborda muito do que se discute atualmente acerca das mazelas que afligem homossexuais em todo o mundo. A depender do estudo abordado, pessoas gays são entre duas e dez vezes mais propensas a cometerem suicídio do que heterossexuais, assim como são duas vezes mais propensas a passarem por episódios depressivos em suas vidas (HOBBES, 2017).

Assim, muito antes do conhecido slogan dos anos 1990 "We're here, we're queer, get used to it!' [Estamos aqui, somos queer, acostume-se a isso] da organização ativista estadunidense LGBTQI+ Queer Nation, o personagem Harold, o anti-herói da história, desafiava Michael a encarar sua sexualidade de maneira resoluta ao afirmar que, apesar da abnegação, ele sempre seria um homossexual. "Sempre, Michael. Sempre." (CROWLEY, 2008, p. 108, nossa tradução ${ }^{21}$ ). Uma afirmação de identidade, portanto, talvez não condizente com o que se preconizava no momento, mas ainda assim relevante até hoje.

\section{Conclusão}

Tanto a peça quanto o filme The Boys in the Band são um registro instantâneo de um tipo particular de interação em um momento específico da história, mas também uma janela para as emoções e inquietações com as quais homens gays precisavam lidar a fim de lutar contra a homofobia e construir suas subjetividades entre iguais, ou, ao menos, entre semelhantes. O ponto central dessa festa de aniversário é que ela definitiva e desafiadoramente não se assemelha a um evento social de homens heterossexuais. Essa entrada em um local antes escondido a portas fechadas, pelo menos para o público heterossexual, foi o ponto mais provocativo para essas pessoas quando a peça e o filme estrearam, entre o final de uma década e o início da seguinte. 
Com isso, ao considerarmos que, até os anos 1960, os gays eram marginalizados e invisíveis em representações artísticas voltadas ao público geral, The Boys in the Band ajudou a criar um diálogo maior a respeito da homossexualidade - a despeito das críticas oriundas do próprio Movimento Gay em seu levante pós-Stonewall, no final daquela década. Segundo John D’Emilio, professor de história e de estudos de gênero e da mulher da Universidade de Illinois, "as condições materiais da vida gay, até os anos 60, eram que a maioria dos homens gays tinha pouca oportunidade para se conceberem como parte de uma coletividade" (D’EMILIO, 1992, p. 107, nossa tradução ${ }^{22}$ ). As expectativas se transformaram, assim como o horizonte ao qual se direcionavam os olhares da militância.

Apesar da reputação negativa em torno da obra de Crowley, o impacto de uma peça e de um filme de temática $100 \%$ homossexual reverberou em todo o mundo e por muito tempo. Nos dias atuais, por exemplo, percebe-se que personagens gays são tão comuns e tão assimilados como nicho de mercado dentro da lógica de absorção total do capitalismo tardio que lhes é permitido, inclusive, demonstrar seus defeitos e imperfeições, um legado diretamente relacionado à proposta de The Boys in the Band. Ademais, o interesse pela peça e o filme ganharam um novo fôlego com a versão da Broadway estreada em 2018 ${ }^{23}$, com um elenco de atores célebres, dentre os quais alguns gays assumidos publicamente - um ponto de diferença histórica relevante em relação ao pioneiro elenco original ${ }^{24}$, o que atraiu ainda mais publicidade à nova montagem.

Com isso, acrescenta-se uma nova faceta à recepção do texto de Crowley (2008). O texto pode ser o mesmo, mas o horizonte de expectativas do novo público já reflete uma gama de diferenças no que se refere à apreciação de como essa "vida gay" foi retratada por Crowley e ao que isso significa - e enseja - cinquenta anos depois.

Notas

1. Adotamos aqui a denominação contemporânea "Movimento LGBTQI+" (sigla referente à junção de lésbicas, gays, bissexuais, travestis, transexuais, transgêneros, queer, intersexuais e outros). No entanto, por vezes "Movimento Gay" torna-se mais fiel à nomenclatura adotada no contexto da militância homossexual existente no período de lançamento da peça e do filme aqui abordados. Além disso, para evitar incorrer em anacronismos indesejados, ressalte-se que, nesse momento e no contexto anglo-saxão, as pessoas que desviavam da norma cisheterossexual eram chamadas de forma grupal e genérica de "homossexuais".

2. No original: "Kauffman's article was, 'Isn't it about time that one of these homosexual writers writes a play that's openly about his own experience?'. And I thought that was a very, very good point" (STONEWALL, 2009).

3. Entre os acontecimentos importantes daquele ano, o Maio de 1968, marcado pelos movimentos insurgentes na França e pela mobilização de estudantes e das classes operárias em greves gerais pelo país, influenciaria diversos acontecimentos similares ao redor do mundo, tornando-se ícone de um período em que diversas transformações de valores, especialmente entre os jovens, estavam postas. No Brasil, em 26 de junho, aconteceria a Passeata dos Cem Mil, que desafiava valores institucionais e o status quo político e social. Porém, em dezembro de 1968, seria decretado o Ato Institucional no 5 (AI-5) pelo regime militar, instituindo um dos períodos mais duros da ditadura brasileira desde o Golpe Militar de 1964. 
4. Mesmo ano da primeira adaptação da peça aos palcos brasileiros. Essa versão, produzida pelo ator John Herbert (1929-2011) e dirigida por Maurice Vaneau (1926-2007), foi traduzida pelo escritor Millôr Fernandes (1923-2012). Essa tradução, porém, permanece sem publicação oficial.

5. Conta-se que a morte da atriz Judy Garland, um ícone para a comunidade gay à época, em 27 de junho, teria sido um dos motivos para o evento realizado uma semana depois, no Stonewall Inn, palco principal da revolta. Coincidentemente, o título The Boys in the Band foi tirado de uma fala de Garland no filme Nasce uma estrela, de 1954, dirigido por George Cukor (1899-1983).

6. No original: "old' and the 'new homosexuality" (BURKE, 1969, p. 178).

7. No original: "nonliberated homosexuality" (ALTMAN, 1993, p. 178).

8. No original: "It's not always like it happens in the plays, not all faggots bump themselves off at the end of the story" (CROWLEY, 2008, p. 71).

9. No original: "Consider the state of "gay and lesbian" theatrical movies in the United States before 1969. Arguably there was no such thing, just a scattering of gay and lesbian directors, often closeted, making films that were masquerading as massmarket heterosexual fare, albeit with the occasional gay or lesbian actor or subtle wink. If characters were openly identified as gay or lesbian on screen, it was most often for a punch line or tragic demise" (RICH, 2013, p. 3).

10. Ressalta-se que a homossexualidade seria despatologizada pela American Psychiatric Association (APA) apenas em 1973.

11.Em 2019, a 23 ${ }^{\text {a }}$ Parada do Orgulho LGBT de São Paulo teve como tema os "50 anos de Stonewall".

12. No original: "leaving its narrative focus on pre-gay-liberation social life fully intact" (POWELL, 2016, p. 88).

13. No original: “The play's success led to its adaptation into other media. In 1969, A\&M Records released an original cast recording of The Boys in the Band as a double LP. Hollywood producers expressed interest in adapting it to film, but Crowley balked at the changes they proposed and decided to produce the film himself. The filmproduction unit of CBS in that period, Cinema Center Films, agreed to Crowley's terms: it would be shot in New York City, it would use the original cast from the play, Crowley himself would adapt the script, and no extra-diegetic song or musical score would be included" (BELL, 2016, p. 4).

14. No original: "Adaptation is repetition, but repetition without replication. And there are manifestly many different possible intentions behind the act of adaptation: the urge to consume and erase the memory of the adapted text or to call it into question is as likely as the desire to pay tribute by copying" (HUTCHEON, 2006, p. 7).

15. No original: "Writing a screenplay based on a great novel [...] is foremost a labor of simplification. [...] A film has to convey its message by images and relatively few words; it has little tolerance for complexity or irony or tergiversations" (BEGLEY, 2003, apud HUTCHEON, 2006, p. 2).

16. No original: "To show gay people as part of everyday pedestrian locales was to refashion those locales in progressively oriented teleological terms; images of gay people in the city worked as part of a greater cinematic manufacturing of outness that implicitly narrativized a gay transformation"(POWELL, 2016, p. 93).

17. No original: "A consideration of the differences between the modes of engagement of telling and showing, however, suggests quite the contrary: each mode, like each medium, has its own specificity, if not its own essence. In other words, no one mode is inherently good at doing one thing and not another; but each has at its disposal 
different means of expression-media and genres-and so can aim at and achieve certain things better than others" (HUTCHEON, 2006, p. 24).

18. No original: "While The Boys in the Band was deemed a homosexual play as it traversed the United States, abroad it was regarded as an American homosexual play. In fact, many of the reviewers went to great effort to explain that the characters were distinctively foreign. Local audiences were encouraged to enter into the play's world as if tourists to a strange land and were allowed a privileged view of the customs, behaviors, and rituals of the American aboriginals" (WILSON, 2016, p. 149).

19. No original: "Gay liberationists of the 1970s and 1980s actively repudiated the film, constructing an enduring bad reputation for it; sometimes, even now, the very title The Boys in the Band has served as shorthand for a preliberated gay male consciousness characterized by self-loathing, insularity, and narcissism" (BELL, 2016, p. 11).

20. No original: "You show me a happy homosexual, and I'll show you a gay corpse?" (CROWLEY, 2008, p. 112).

21. No original: "Always, Michael. Always" (CROWLEY, 2008, p. 108).

22. No original: "the material conditions of gay life until the 1960s were such that most gay men had little opportunity to conceive of themselves as part of a collectivity" (D’EMILIO, 1992, p. 107).

23. A peça estreou na Broadway para uma temporada limitada no Boothe Theatre. Em 2019, Crowley ganhou, pela primeira vez, um dos prestigiados prêmios Tony, na categoria Melhor Revival de uma Peça. Também assinada pelo diretor da montagem de 2018, Joe Mantello, e com envolvimento do produtor Ryan Murphy, conhecido por seu envolvimento em produções de temática LGBTQI+, como o filme The Normal Heart (2014) e a série Pose (2018-2019), uma adaptação cinematográfica de The Boys in the Band estreou em setembro de 2020 na plataforma de streaming Netflix.

24. Para artistas homossexuais e a cultura gay em geral, a despeito do crescimento e da proliferação de comunidades LGBTQI+, organizações políticas e espaço na mídia ao longo da década de 1970, na década seguinte, a direita cristã promoveu um grande boicote, instigado ainda mais pela epidemia do HIV/AIDS. Temendo represálias e manchas na carreira, os atores de The Boys in the Band não se expunham publicamente em publicações voltadas ao público gay, por exemplo. Vale notar que parte do elenco: Kenneth Nelson, Frederick Combs, Leonard Frey, Keith Prentice e Robert La Tourneaux, além do diretor Robert Moore e do produtor da primeira encenação, Richard Barr, faleceram de complicações em decorrência do HIV/AIDS durante os anos 1980 e 1990. Com exceção do ator Cliff Goman, que morreu de leucemia, e Reuben Greene, cuja morte é incerta, dois atores presumidamente heterossexuais ainda continuam vivos, Laurence Luckinbill e Peter White.

\section{Referências}

ALTMAN, D. Homosexual: oppression and liberation. Nova York: NYU Press, 1993.

BARNES, C. Theater: "Boys in the band" opens off Broadway. The New York Times, Nova York, p. 48, 15 Abr. 1968.

BELL, M. Introduction: on returning to The Boys in the Band. In: BELL, M. The boys in the band: flashpoints of cinema, history, and queer politics. Detroit, Michigan: Wayne State University Press, 2016.

BURKE, T. The new homosexuality. Esquire, Nova York, n. 72, p. 178, dez. 1969.

CEIA, C. Horizonte de expectativas (Erwartungshorizont). In: CEIA, C. (coord.). 
E-Dicionário de Termos Literários, 27 dez. 2009. Disponível em: https://edtl.fcsh. unl.pt/encyclopedia/horizonte-de-expectativas-erwartungshorizont/. Acesso em: 6 mar. 2020.

CLUM, J. M. Still acting gay. Nova York: St. Martin’s Griffin, 2000.

CROWLEY, M. The boys in the band. Nova York: Alyson Books, 2008.

D'EMILIO, J. Making trouble: essays on gay history, politics, and the university. Nova York, Londres: Routledge, 1992.

D'EMILIO, J. Sexual politics, sexual communities: the making of a homosexual minority in the United States, 1940-1970. Chicago: University of Chicago Press, 1998.

FONE, B. Homophobia: a history. Nova York: Picador, 2000.

HOBBES, M. The epidemic of gay loneliness. Huffington Post, 2 mar. 2017. Disponível em: http://highline.huffingtonpost.com/articles/en/gay-loneliness/. Acesso em: 6 mar. 2020.

HUTCHEON, L. A theory of adaptation. Nova York: Routledge, 2006.

JAMESON, F. Marxismo e forma: teorias dialéticas da literatura no século XX. Tradução de Iumna Maria Simon (coord.), Ismail Xavier e Fernando Oliboni. São Paulo: Hucitec, 1985.

JAMESON, F. Periodizando os anos 60. In: HOLANDA, H. B. de. (org.). Pósmodernismo e política. Rio de Janeiro: Rocco, 1991. p. 81-126.

JAMESON, F. Pós-modernismo: a lógica cultural do capitalismo tardio. Tradução de Maria Elisa Cevasco. São Paulo: Âtica, 2002.

JAUSS, H. R. A história da literatura como provocação à teoria literária. Tradução de Sérgio Tellaroli. São Paulo: Ática, 1994.

KAUfFMAN, S. Homosexual drama and its disguises. The New York Times, Nova York, section A, p. 9323, Jan. 1966.

MAKING the boys. Direção e produção: Crayton Robey. Nova York: Crayton Robey, 2010. Documentário, 24'49”. Disponível em: https://www.youtube.com/ watch? $=\mathrm{vz}$ CIsWv0aP4\&t=8s. Acesso em: 6 mar. 2020.

POWELL, R. Gothic spatiality and the limits of gay visibility in The boys in the band. In: BELL, M. The boys in the band: flashpoints of cinema, history, and queer politics. Detroit, Michigan: Wayne State University Press, 2016. p. 88-112.

QUINALHA, R. H. O mito fundador de Stonewall. CULT, São Paulo, n. 246, 3 jun. 2019. Disponível em: https://revistacult.uol.com.br/home/o-mito-fundador-destonewall/. Acesso em: 6 mar. 2020.

RICH, B. R. Before the beginning: lineages and preconceptions. In: New Queer Cinema: The Director's Cut. Durham: Duke University Press, 2013.

SCHWARZ, R. A lata de lixo da história. 2. ed. rev. e ampl. São Paulo: Companhia das Letras, 2014.

STONEWALL Special: looking back at "The boys in the band". Theater Talk. New York: PBS, 20 June 2009. Disponível em: https://www.youtube.com/ watch?v=fVcwo6vtPZQ. Acesso em: 6 mar. 2020.

WESTSTRATE, N. M.; MCLEAN, K. C. The rise and fall of gay: a cultural-historical approach to gay identity development. Memory, v. 18, n. 2, p. 225-240, 2010. DOI: https://doi.org/10.1080/09658210903153923.

WILSON, J. “"Who does she hope to be?" Celluloid ghosts, queer utopias, and The Boys 
onstage. In: BELL, M. The boys in the band: flashpoints of cinema, history, and queer politics. Detroit, Michigan: Wayne State University Press, 2016. p. 141-162.

Recebido em: 06/07/2020

Aceito em: 13/10/2020 